\title{
SABERES DOS PROFESSORES DE EDUCAÇÃO FÍSICA DOS ANOS FINAIS DO ENSINO FUNDAMENTAL
}

DOI: 105902/0102830819058

Data de Submissão: 08/08/2015

Data de Aprovação: 14/12/2015

\section{Caroline Moesch Cardoso}

Centro Universitário Univates caroline@universo.univates.br

\section{Silvane Fensterseifer Isse}

Centro Universitário Univates silvane@univates.br

RESUMO: Esta pesquisa objetivou analisar como os professores de Educação Física que atuam nos Anos Finais do Ensino Fundamental compreendem os saberes trabalhados em aula. Trata-se de um estudo qualitativo. Foram entrevistados cinco professores de Educação Física que atuam em escolas municipais, estaduais e privadas do município de Lajeado/ RS. A pesquisa evidenciou que a compreensão sobre os saberes está intimamente ligada à formação inicial dos professores, notadamente influenciada pela esportivização, o militarismo e a medicina higiênica. Em relação aos saberes trabalhados, evidenciou-se a questão da disciplina, das relações interpessoais, dos esportes e da socialização, construídos através das práticas corporais.

Palavras-chave: Educação Física. Saberes. Docentes. Ensino Fundamental.

\footnotetext{
${ }^{1}$ O presente trabalho não contou com apoio financeiro de nenhuma natureza para sua realização.
} 


\section{Introdução}

Pesquisar a proposta de trabalho dos professores nas aulas de Educação Física (EFI) tem sido algo mais frequente, ainda que seja um tema pouco investigado. Quando falamos dos Anos Finais (AF) do Ensino Fundamental (EF), nos referimos a adolescentes, que trazem para sala de aula seus anseios e desejos. As aulas de EFI podem se tornar um espaço de manifestação desses desejos e de construção do conhecimento, já que essa disciplina permite um contato maior entre os alunos, possibilitando a expressão de sentimentos através do corpo, em um amplo espaço físico, o que para outras disciplinas se torna algo mais restrito (REZER, 2007).

O Referencial Curricular do Estado do Rio Grande do Sul para a Área de Linguagens Códigos e suas Tecnologias - Artes e Educação Física propõe que o papel da disciplina na área escolar não se trata apenas de "tornar os alunos fisicamente aptos" (RIO GRANDE DO SUL, 2009, p. 113), mas de constituir-se em tempo e espaço de experimentações diversas, incluindo diferentes práticas corporais, em "diversos contextos históricos" (GONZÁLEZ; FRAGA, 2012, p. 37), ou seja, um espaço de construção de conhecimento.

A EFI tem sido, historicamente, tratada como uma disciplina do fazer, do praticar, secundarizando-se, muitas vezes, a reflexão acerca dos saberes que nela são colocados em movimento e que a constituem como campo de conhecimento.

Esta pesquisa teve como objetivo analisar como os professores de EFI que atuam nos Anos Finais do Ensino Fundamental compreendem os saberes trabalhados em sala de aula e por que, e de que forma, os escolhem.

\section{Procedimentos metodológicos}

A pesquisa foi de caráter qualitativo. Para a coleta de informações foram entrevistados cinco professores de EFI que atuam nos AF do EF em escolas das redes municipal, estadual e privada do município de Lajeado/RS. Foram entrevistadas três mulheres, duas delas atuantes nas redes municipal e estadual 
e uma delas na rede privada, e dois homens: um deles atuante na rede privada e outro na rede municipal. Quatro entrevistados estão formados há mais de vinte anos e um há sete anos. Todos atuam na EFI escolar e em sala de aula há mais de vinte anos.

As entrevistas, semiestruturadas, foram gravadas, transcritas e devolvidas aos participantes para aprovação. Além das entrevistas, fez-se uso de diário de campo. Os professores entrevistados receberam e assinaram o Termo de Consentimento Livre e Esclarecido, no qual foram apresentados os cuidados éticos, os objetivos e os procedimentos da investigação. Os nomes dos participantes foram substituídos, neste texto, pelos pseudônimos Edel, Mari, Pedro, Alberto e Rosa.

A análise das informações se deu pela triangulação das informações coletadas no campo com os referenciais teóricos e as interpretações das pesquisadoras. Foram construídas três categorias de análise, as quais passaremos a apresentar: 1) saberes e relações com a formação docente, 2) saberes da Educação Física nos Anos Finais e 3) definição dos saberes e metodologias de trabalho.

\section{Saberes e relações com a formação docente ${ }^{2}$}

As falas dos professores entrevistados sugerem uma forte ligação entre os saberes trabalhados em suas aulas nos AF e a formação acadêmica recebida. Para quatro dos professores entrevistados, a formação está intimamente ligada a fatos históricos da EFI escolar. Os relatos mostram que a formação acadêmica desses professores foi baseada nos princípios militaristas, ainda significativos nos anos 80, assim como a esportivização e os princípios da medicina higiênica. Observa-se que a formação desses professores, que objetivava a disciplina e a aprendizagem de habilidades motoras, orienta os saberes predominantes em suas aulas de EFI nas escolas hoje. O quinto entrevistado formou-se no ano de 2007.

\footnotetext{
${ }^{2} \mathrm{~A}$ formação docente, neste texto, está sendo compreendida como a formação deliberada e sistemática dos professores, por meio de organização curricular, com base na legislação de ensino vigente (SAVIANI, 2009).
} 
Foi possível perceber uma mudança em relação à metodologia utilizada em sua formação, quando comparada aos demais.

Para cada professor, a formação docente se deu de um modo diferente. A formação acadêmica dos quatro professores que se formaram nos anos 80 se deu na mesma universidade. Esses professores tiveram uma formação basicamente prática $^{3}$. Praticavam o tempo todo esportes como futebol, handebol, basquete, atletismo, natação, judô, além de dança e ginástica, entre outras disciplinas curriculares. As aulas teóricas se baseavam em regras esportivas, as quais eram cobradas em provas práticas e teóricas. A disciplina de cinesiologia foi bastante ressaltada nas falas, assim como a disciplina de ginástica, consideradas como as mais difíceis do curso, as que exigiam mais conhecimentos da parte biológica.

Para a realização das aulas, havia divisões de turmas. Uma era mista e outra composta apenas por mulheres. A perspectiva biologicista da EFI aparece na questão das diferenças de gênero: atividades para meninos e atividades para meninas, apoiadas na crença de que o corpo dos meninos podia mais, pois eram mais fortes, e o corpo das meninas podia menos, por serem consideradas frágeis. Sobre a divisão de gênero, Sousa (1994) destaca que as escolas, já em 1909, ministravam aulas de EFI separando meninos e meninas.

Para as meninas, as aulas tinham como objetivo a formação de donas de casa e a preparação para a maternidade. Já os meninos, segundo Vago (1999), aprendiam os métodos militares, que seriam muito importantes para o trabalho e a defesa do país. Eles praticavam atividades relacionadas à marcha e trabalhos de força física.

Quanto às aulas, os professores entrevistados, quando questionados sobre sua formação, apontam um viés prático. Edel coloca: "Tudo era prática, muita prática". No período em que se deu sua formação, a ideia que se tinha era de estudantes

\footnotetext{
${ }^{3}$ A expressão "prática" foi usada pelos professores para referir-se à prática de exercícios físicos (esportes, jogos, dança, ginástica...). Formação bastante prática, portanto, seria uma formação em que experimentar corporalmente os movimentos de diferentes práticas corporais ocupava boa parte do currículo.
} 
e professores atletas: saber praticar os desportos com bastante habilidade era o objetivo principal. Nesse contexto, ressalta-se nas entrevistas dos professores, formados nos anos 80 , a ideia de que os alunos precisam aprender pelo menos as principais habilidades dos esportes como, por exemplo, dar um toque no vôlei ou arremessar uma bola no basquete, para, quando saírem da escola, terem desenvolvido estas habilidades, seja para se divertirem com amigos, seja para praticarem em uma atividade diária.

A professora Mari reforça este pensamento, dizendo que: "as disciplinas eram mais direcionadas aos esportes". Os professores em formação, por sua vez, buscavam ampliar sua performance esportiva, com o intuito de ensinar, em suas aulas, a técnica dos esportes. Essa prática remete ainda à esportivização, mesmo que já não voltada a números, premiações e pódios.

"Educar os corpos", higienizar os corpos, visando à saúde, bem-estar e manutenção da disciplina ainda eram objetivos que se faziam presentes na formação dos professores de EFI nos anos 80. Práticas esportivas eram trabalhadas com ênfase na formação acadêmica com o objetivo de tornarem os professores de EF ótimos praticantes, dominantes das habilidades motoras e das modalidades esportivas em geral, para atuarem nas escolas.

A fala da professora Edel explicita essa formação: "Não tinha formação do professor. Tinha psicomotricidade, anatomia, cinesio, todas essas aí, tinham”. Não havia nas disciplinas, um momento de reflexão da prática vivenciada, o que hoje se observa com mais clareza em disciplinas de "práticas" da Educação Física. Basquetebol, voleibol, entre outras, são disciplinas da formação que hoje oferecem oportunidades para que os acadêmicos possam compreender os saberes que estão sendo trabalhados ou construídos com estes esportes.

O professor Pedro, com uma formação mais recente traz outro olhar sobre sua formação em aulas práticas. Nas suas palavras, sua formação:

[...] foi mais pedagógica, foi mais voltada para tu pensares como foi a aula de Educação Física, dar um significado, para o aluno participar da 
aula. Agora se oportuniza muito mais, para o aluno experimentar, pelo gosto dele mesmo (PEDRO).

Refletindo sobre a fala do professor Pedro, percebe-se uma compreensão de saberes que são construídos durante a formação dos professores, pois a partir do momento em que os desportos passam a ser vistos não apenas como momento de aprimorar habilidades motoras, cria-se uma nova relação de saber: um saber que é construído em interação entre professor e aluno.

O fato de os professores terem aulas mais voltadas para práticas corporais em sua formação, de alguma forma amplia a possibilidade de que eles ofereçam o mesmo para seus alunos. Neste sentido, Figueiredo (2004, p. 92) diz que "a experiência social do aluno, construída durante sua trajetória, dentro e fora da escola, interfere, influencia e/ou, de alguma forma, modela o perfil de formação inicial".

Nesse contexto, destaca-se o fato de duas professoras retomarem os estudos - curso de Especialização em Educação Física Escolar. As duas professoras, Mari e Edel, enfatizam a importância desse curso na sua trajetória profissional. Citam autores e relatam que passaram a ter um novo olhar sobre a EFI escolar. A formação continuada, pois, contribui para a constante reflexão sobre o trabalho docente e para possíveis transformações no fazer pedagógico.

\section{Saberes da Educação Física nos Anos Finais}

A EFI, de acordo com o Referencial Curricular do Rio Grande do Sul, está inserida na área das Linguagens, Códigos e suas Tecnologias. A EFI, como linguagem, pode ser compreendida como linguagem corporal, isto é, como o corpo nos ensina ou como com o corpo somos capazes de aprender. Inserem-se na área das Linguagens, Códigos e suas Tecnologias as práticas sociais e de representação. Movimentos que historicamente estão ligados à saúde corporal, ganham novos contornos através de práticas expressivas como teatro, dança, 
lutas, práticas esportivas, atividades lúdicas, entre outras, que levam o aluno a desenvolver competências e habilidades (RIO GRANDE DO SUL, 2009).

Dessa forma, a EFI se insere nessa grande área, juntamente com as disciplinas de Artes, Literatura, Língua Portuguesa e Língua Estrangeira Moderna. Esta aproximação causa estranheza em certas escolas, que ainda vêem a EFI associada à área das Ciências da Natureza. O Referencial Curricular, por sua vez, não tem sido um documento de referência para os professores investigados, ainda que se constitua num esforço bastante interessante de sistematização dos temas da cultura corporal de movimento.

Durante as entrevistas, percebeu-se que os saberes dos professores participantes da pesquisa estão sendo compreendidos como os conteúdos das aulas. Porém, saberes são mais que conteúdos (FIGUEIREDO, 2004). Eles são conhecimentos. Saberes vão além das práticas esportivas ditas "normais". Essa foi uma expressão usada pelos professores ao se referirem aos conteúdos mais trabalhados em aula: vôlei, futebol, basquete e handebol. Os professores definiram como aulas "normais" aquelas em que os alunos se dirigem à quadra, ou outro espaço amplo, e realizam alguma prática esportiva. Já as aulas "não normais", eram as aulas de ginástica, aulas em que se desenvolviam projetos sobre postura, alimentação, trabalhos de pesquisa. As aulas "normais, pode-se dizer, são aquelas que sustentam a tradição da EFI e mantém a hegemonia do esporte.

O saber tem relação forte com o aprender, com o fato de obter informações sobre, ou até mesmo adquirir conhecimento em relação a, levando o professor a ter domínio de uma área de conhecimento a partir de relações construídas entre o saber teórico e a prática que constrói (FIGUEIREDO, 2004). Refere-se a um conhecimento de como se apropriar de uma aprendizagem. É conhecer de tal forma que permite a transformação de realidades de alunos, compreendendo-as de acordo com cada singularidade com que se depara em sala de aula. Assim, possibilita o atendimento a todos os alunos em suas particularidades. É uma forma mais profunda de se relacionar com um esporte, por exemplo. 
Entre saberes corporais e saberes conceituais, à EFI, como disciplina, compete:

[...] esporte, ginástica, jogo motor, lutas, práticas corporais e expressivas, práticas corporais junto à natureza e atividades aquáticas. [...] estudo das representações sociais que constituem a cultura do movimento e afetam a educação dos corpos de um modo geral [...] (RIO GRANDE DO SUL, 2009, p. 118).

Levando em conta o que o Referencial Curricular propõe, sente-se a necessidade de os saberes atravessarem os conteúdos propostos para as aulas de EFI. Cada um dos temas abre caminho para que se trabalhem outros "subtemas", oportunizando ao professor autonomia sobre os saberes que deseja trabalhar (RIO GRANDE DO SUL, 2009).

Referindo os saberes dos professores entrevistados, foi possível perceber que as práticas corporais ligadas aos esportes, as "aulas normais", estão sendo trabalhadas nas escolas. Em todas as entrevistas se falou delas: como são trabalhadas, quais os diferentes materiais utilizados e as diversas adaptações feitas para que todos os alunos possam participar. Em relação ao uso de materiais diferentes e às adaptações, percebe-se que há, por parte de todos os professores pesquisados, uma atenção para: saber respeitar as diferenças, conviver em grande grupo, socialização entre os alunos, exercício físico e saúde. Essa percepção se mostra visível na fala da professora Edel:

Até o $5^{\circ}$ ano, considero importante trabalhar atividades relacionadas ao brincar: correr, rolar, lançar, pular... de forma lúdica, além de atividades pré-desportivas. Já do $6^{\circ}$ ano em diante, ou seja, nos anos finais, procurar relacionar as aulas com o esporte. E aproveitando as valências que os esportes trazem como: flexibilidade, elasticidade, respeito com outro, habilidades, disciplina, atitude além é claro trabalho em equipe.

Percebe-se que a professora Edel propõe aos alunos partirem de determinados níveis de exercícios para níveis mais complexos de atividades. Para a construção de saberes em sala de aula, ela ensina a disciplina, desejando que os alunos aprendam, incorporem, saibam "comportar-se". A disciplina requerida por essa professora remete à tradição histórica da EFI: a higienização dos corpos, a disciplina 
dos mesmos, a busca de corpos saudáveis e disciplinados, ao reiterar o saber se portar, ser organizado, ir para a EFI caminhando, com calma.

Já a professora Mari, quanto aos saberes trabalhados, diz:

Considero importante na EFI, todos os conteúdos nas dimensões atitudinais, procedimentais e conceituais e é o que eu procuro trabalhar. $\mathrm{O}$ aluno deve conhecer seu corpo, como exemplo: frequência cardíaca, ver como está antes da atividade física e depois. [...] EF não é só esportes.

A professora menciona as atitudes dos alunos durante as aulas como sendo o foco do seu trabalho. Pensa que a EFI não se resume aos esportes, mas abrese à possibilidade de conhecimento de si, do seu corpo e do corpo do outro. $\mathrm{O}$ modo como ela trabalha o "conhecer o corpo" é um trabalho voltado a conhecer o próprio corpo, seja em relação às reações orgânicas diante de uma sessão de atividades físicas, seja conhecendo limites, necessidades, flexibilidade, interação, enfim, um corpo produzido nas suas múltiplas dimensões. Quando realizamos o trabalho de frequência cardíaca, aponta a professora, podemos conhecer o nosso corpo de forma mais orgânica-biológica.

Mas conhecer o corpo nas aulas de EFI relaciona-se, também, aos sentimentos vividos pelo corpo, às maneiras que o corpo tem de se expressar, o que se traduz numa possibilidade de conhecer o corpo numa dimensão sociocultural, segundo a professora Mari. Nos Parâmetros Curriculares Nacionais, destaca-se um objetivo, nesse sentido, para a EFI: "Vivências corporais que ampliem a percepção do corpo sensível e do corpo emotivo" (BRASIL, 1998, p. 76).

O professor Alberto coloca como fundamental, em suas aulas, que os alunos, nos AF,

[...] vão adquirindo coordenação para depois desenvolver os esportes, também essa parte de sociabilização entre eles. O professor é muito importante ali, na minha maneira de ver, na parte técnica na EF, ali nos AF, o aluno já tem que saber o básico do fundamento dos esportes [...] aluno meu não pode chegar, ou melhor, sair da aula de EF, sem saber que aquela aula foi importante para ele.

Nessa fala, a visão das práticas corporais sistematizadas se sobressai em relação a outras práticas corporais a serem trabalhadas na EFI. Quanto à parte 
técnica, como é chamada por Alberto, vista como a mais importante, percebe-se uma espécie de espelho em relação a seu processo de formação, visto que o mesmo teve por base o modelo da esportivização e do militarismo, trabalhando com seus alunos os saberes que foram significativos para ele durante sua formação acadêmica. Já outro olhar pode ser percebido quando o professor fala em "saber que aquela aula foi importante para ele". Mostra que a aula tem objetivos, que o professor pensa nos seus alunos no momento do seu planejamento, procurando incluir a todos. Entram aqui os saberes da ordem do afeto, saberes sociais, em que o professor reflete sobre suas aulas, acreditando que o seu fazer pedagógico, na disciplina de EFI, resulta numa aprendizagem significativa.

Nesse sentido se situa também a visão do professor Pedro em relação à EFI escolar e aos saberes que considera importantes:

[...] a EFI é uma prática social e eu penso que o mais importante é mostrar que existem muitas perspectivas de movimentos, de atividades, que eles podem usar nas horas de lazer, usar nas relações com as outras pessoas. Acho que isso é fundamental, tu conseguir trazer para eles o maior número de experiências possíveis.

O professor Pedro, ao falar em "prática social", está trazendo saberes que se constituem em experimentações, em troca de informações, de conhecimentos, de desejos, em que os alunos são protagonistas das aulas de EFI. Além das aulas "normais", proporciona aos alunos oportunidades de construção do conhecimento, o que se aproxima da experiência de formação vivenciada no seu segundo período acadêmico: um período em que não teve somente a prática, mas que as aulas práticas proporcionavam também momentos de reflexão, para que o professor repensasse sua prática e seus objetivos para com ela em sala de aula.

Um olhar diferenciado em relação às demais falas quanto ao que são os saberes da EFI encontra-se na fala da professora Rosa: "Eu coloco eles junto com a prática, não pode ser só a prática ou só os saberes". Nessa fala vê-se um trabalho voltado a não distinguir a EFI em movimentos estanques: teoria de um lado, prática de outro. Percebe-se a perspectiva de práxis, em que a teoria 
alimenta a prática e a prática transforma a teoria, o que é diferente a pensar que a prática simplesmente corrobora a teoria.

Em outra fala, a professora Rosa faz uso da palavra "contextualizar" para se referir à sua prática educativa. Para ela, contextualizar "não quer dizer que tu tenhas que ir para uma sala de aula para trabalhar o conteúdo da disciplina", o que remete a pensar que os saberes estão associados à capacidade de contextualização da prática. Ou ainda, o saber, para ela, relaciona-se a mostrar para os alunos as práticas, sem dissociá-las da prática de reflexão e pensamento. Nas suas palavras:

[...] existe a modalidade dentro da aula de EF, mas sempre contextualizando, falando da história, mostrando como é aquele esporte, pode até ser uma aula teórica, ou prática, mas nunca deixando eles sozinhos, fazendo exercícios por fazer, chegando ao final da aula, ou da semana, do bimestre, e perguntar o que a gente aprendeu? (ROSA).

A análise das falas dos professores entrevistados em relação aos saberes trabalhados na $\mathrm{EFI}$, nos $\mathrm{AF}$, ao mesmo tempo em que permitiram compreender em que se constituem esses saberes, trazem à tona uma lacuna quanto à cultura corporal de movimento ${ }^{4}$, às lutas, à ginástica, à dança e às atividades expressivas, que não foram citadas por nenhum dos professores como saberes a serem trabalhados em sua prática educativa. Em suas falas não foi possível perceber que estes saberes são tratados com a mesma importância que os relativos aos esportes.

Destaca-se o fato de todos os professores participantes estarem atentos aos sentimentos e afetos com relação ao trabalho em grupo e respeito às diferenças, mas em relação à cultura corporal do movimento não se percebeu um olhar mais apurado. O que foi ressaltado com ênfase pelos professores é o fato de os alunos saírem das aulas com o conhecimento dos esportes e de seus fundamentos básicos. Esses aspectos contemplam em parte o que poderiam ser os saberes

\footnotetext{
${ }^{4}$ Temas a serem tratados pedagogicamente pela Educação Física, os quais contribuem para a problematização das realidades sociais e para a expressão dos sentidos/significados construídos para o movimento e não se constituem em meras expressões de uma natureza apenas biológica do ser humano (COLETIVO DE AUTORES, 2005).
} 
em relação aos esportes, os quais contemplam o aprender fundamentos e o jogo, saber usufruir do esporte para a vida em sociedade e, ainda, a reflexão e apreciação crítica, contribuindo para uma forma pessoal de praticá-lo.

\section{Definição dos saberes e metodologias de trabalho}

Tratando-se de escolas de diferentes redes de ensino, poderíamos vir a ter diversas formas de definição de saberes, mas ocorreu que todas elas elencam seus saberes de forma muito parecidas. Os professores relatam que ocorre uma reunião no início do ano letivo, em que se encontram todos os professores de EFI da escola. Neste momento, elencam o que será trabalhado em EFI em todas as turmas. O grupo de professores procura contemplar os Planos de Ensino para a disciplina, sem ferir a autonomia dos professores para trabalharem os saberes que acreditam ser importantes para seus alunos.

A professora Edel, em seu relato, enfatiza que, na sua escola, nem sempre os professores concordam com os saberes a serem trabalhados. Desta forma, cada professor, confere graus de importância de forma diferenciada aos saberes combinados em grupo:

Decide-se nas reuniões dos professores o projeto que faremos. Falamos com os demais professores o que cada professor prioriza e o que acha mais significativo, importante para o aprendizado dos alunos. Por exemplo: o ensinamento do jogo de xadrez: é importante a meu ver, porque é uma forma de armar estratégias, de raciocinar, de pensar, $[\ldots]($ EDEL).

O que a professora traz em sua fala é o que se observa em relação à formação dos professores. Cada professor traz uma bagagem, que se constitui durante a formação acadêmica, durante as vivências sociais e chegam à sala de aula, combinados com os saberes acordados em grupo para serem trabalhados com os alunos.

Dentro dos saberes elencados, cada professor possui uma metodologia de trabalho e cada escola em particular a sua. Foi possível perceber que as professoras Edel e Mari, atuantes nas duas redes estadual e municipal trabalham 
de forma semelhante. Elas utilizam, em suas aulas, todos os espaços abertos que as escolas proporcionam, materiais diversos como bolas, cordas, cones, colchonetes e também materiais que confeccionam, que não são disponibilizados pelas escolas. O que diferencia o trabalho das duas é a metodologia. A professora Edel ministra, uma vez por semana, aulas teóricas trazendo para os alunos textos informativos e propostas de trabalhos em grupo e individual. Cada aluno possui um caderno de EFI contendo os conteúdos para estudo. Já a professora Mari, faz uma aula teórica por mês, trabalhando com seus alunos algumas regras de esportes e demais assuntos.

Na mesma rede municipal, o professor Pedro trabalha de forma diferente das professoras Edel e Mari. Ele ressalta que a teoria não se faz necessária em uma sala de aula. Diz: "Eu não dou aula de regras no quadro, eu dou aula de regra na quadra. Lá eu explico para eles e eles participam e experimentam, vivenciam a aprendizagem, constroem saberes com o corpo" (PEDRO). A sua escola oferece áreas diversas para prática da EFI e trabalha com elementos da natureza na área verde, explorando árvores com cordas, trabalhando com os alunos o slackline, entre outros esportes de aventura possíveis na escola, proporcionando para os alunos diferentes vivências corporais. Demonstra ser um professor em busca do novo, de experiências de movimento que contribuam para aprendizagens de seus alunos, com a preocupação de lhes possibilitar práticas educativas com sentido.

Na mesma rede de ensino se observou três metodologias diferentes, conferindo a cada uma delas uma mescla de autoria combinada com o que cada professor estudou, aprendeu, vivenciou, praticou e articulou como conteúdo significativo a ponto de ser levado em sala de aula com uma metodologia própria, garantindo sentido para a aprendizagem dos alunos.

$\mathrm{Na}$ rede privada de ensino, tem-se uma metodologia semelhante entre as escolas. As mesmas servem-se, em suas práticas de ensino, da distinção de sexo como elemento de organização das aulas, de modo a garantir as aprendizagens, 
de acordo com o que foi previsto no planejamento da escola e, por extensão, nos planos de ensino. A distinção de sexo nas aulas de EF faz parte das normas das escolas. Em uma delas fica evidente a crença de que os meninos, nesta idade, são mais agitados, competitivos e acabam inibindo as meninas na participação das práticas esportivas. Em função disso, as turmas são divididas em turma de meninos e turma de meninas, sendo a turma de meninas ensinada por uma professora e a de meninos por um professor. Neste caso, temos o professor Alberto, que faz críticas a essa divisão mas acata a decisão da escola, e a professora Rosa, que aprova a divisão.

Em entrevista, o professor Alberto citou que explora todos os ambientes da escola, utilizando o maior número de materiais possíveis, pois a escola privada fornece todos os materiais que o professor solicita para suas aulas. Como metodologia de avaliação, realiza três trabalhos (provas) durante o ano, sendo elas referentes aos assuntos trabalhados em aula sobre os esportes. Nas provas, oferece aos alunos um minuto de troca de informações com os colegas, com o intuito de que possam esclarecer dúvidas.

Embora haja a divisão por sexo a partir da "oitava", como refere a professora Rosa, em algumas ocasiões as turmas trabalham juntas, principalmente quando os professores planejam circuitos de atividades. A professora Rosa também trabalha com projetos voltados para as necessidades de cada turma, paralelos às demais atividades, explorando o vasto espaço oferecido pela escola e todos os materiais disponibilizados aos professores.

Como podemos observar, as escolas privadas oferecem um maior número de materiais, mas em nenhum momento os professores das redes municipal e estadual mencionaram deixar de trabalhar qualquer modalidade esportiva nas aulas por falta de materiais, pelo contrário, citaram confeccionar materiais quando necessário.

A organização da aula de EFI por diferença de sexo, na escola privada, remete ao aos princípios de sua institucionalização escolar. Nas escolas públicas essa 
separação não acontece. Estas, pois, se mostram mais próximas do que prevê a legislação em vigor, quanto a alguns dos objetivos da disciplina: integração, socialização e conhecimento de diferentes culturas.

\section{Considerações finais}

As falas e reflexões apresentadas pelos professores entrevistados sugerem alguns apontamentos que se tornam relevantes à disciplina de EFI na escola e também em contextos não escolares. Os saberes de cada professor são importantes para o planejamento de suas aulas de EFI. A questão que fica em aberto - em razão de não ter sido mencionada de forma mais evidente nas entrevistas - é por que os professores entrevistados trabalham menos em suas aulas, ou deixam de trabalhar, os múltiplos saberes da cultura corporal do movimento.

Os saberes da cultura corporal do movimento não tiveram expressão nas falas dos entrevistados. São saberes que podem ser trabalhados, por exemplo, nas aulas de futebol, basquetebol e voleibol, diferenciando o modo de condução destas práticas, por cada professor, com abertura à cultura corporal do movimento.

Foi possível perceber que os saberes dos professores de EFI que atuam nos AF do EF possuem forte relação com a sua formação acadêmica. Esta formação está relacionada com os métodos pedagógicos trabalhados pelos professores do curso de EFI da instituição de ensino em que se formaram professores. Nesse aspecto, os professores entrevistados apropriam-se dos saberes durante o curso, tomando-os para si, juntamente com as relações interpessoais que constroem ao longo da sua trajetória acadêmica.

Foi possível compreender, a partir dos relatos dos professores formados nos anos 80 , que a sua formação está marcada por aspectos históricos significativos do ensino de EFI: o militarismo, os métodos ginásticos, a esportivização e a medicina higiênica. São aspectos que perpassaram as metodologias das aulas de formação, valorizando as práticas esportivas e o domínio das habilidades motoras, visando à formação acadêmica, apta em transmitir corretamente a parte técnica. 
A formação dos professores nos anos 80 , quando comparada com a formação em 2007, traz elementos que diferenciam a metodologia utilizada em suas aulas. $O$ professor, formado mais recentemente, tem em sua formação acadêmica disciplinas mais voltadas às questões didáticas e pedagógicas, as quais possibilitam reflexões sobre os saberes do campo da EFI escolar e de suas práticas. São essas reflexões que favorecem maior abertura para a construção de uma visão crítica, tanto por parte da escola como um todo como também por parte dos alunos em relação à disciplina da EFI na escola e de sua prática em contextos não escolares.

A relação direta que foi possível perceber entre formação e prática docente nos mostra que a formação continuada é fundamental para que os professores reflitam sistematicamente sobre o seu trabalho. Nesse sentido, a formação continuada pode contribuir para a construção de práticas pedagógicas dinâmicas, inventivas e que produzam sentido nos Anos Finais do Ensino Fundamental.

\section{Referências}

BRASIL. Secretaria de Educação Fundamental. Parâmetros Curriculares Nacionais: Educação Física/Secretaria de Educação Fundamental. Brasília: MEC/SEF, 1998.

FIGUEIREDO, Zenólia. Formação docente em Educação Física: experiências sociais e relação com o saber. Movimento, Porto Alegre, v. 10, n. 1, p. 89-111, janeiro/abril de 2004.

GONZÁLEZ, Fernando. J.; FRAGA, Alex. Afazeres da Educação física na escola: planejar, ensinar, partilhar. Erechim: Edelbra, 2012.

REZER, Ricardo. Relações entre conhecimento e prática pedagógica no campo da educação física: pontos de vista. Revista Motrivivência, Ano XIX, № 28, P. 38-62 Jul./2007. Disponível em: https://periodicos.ufsc.br/index.php/motrivivencia. Acesso em: 15 jun. 2014. 
RIO GRANDE DO SUL. Secretaria de Estado da Educação. Departamento Pedagógico. (Org.). Linguagens, códigos e suas tecnologias: Arte e Educação Física. Caderno do professor. Porto Alegre: SE/DP, v. 2, 2009b.

SAVIANI, Dermeval. Formação de professores: aspectos históricos e teóricos do problema no contexto brasileiro. Revista Brasileira de Educação, v. 14, n. 40, p.143-155, jan./abr. 2009. p.143-155.

SOARES, Carmen L.; TAFFAREL, Celi N. Z.; VARJAL, Elizateh. Metodologia do ensino de educação física. São Paulo: Cortez, 2005.

SOUSA, Eustáquia S. Meninos à marcha! Meninas à sombra: a história do ensino da educação física em Belo Horizonte (1987-1994). 1994. Tese (Doutorado em Educação) - Universidade Estadual de Campinas, Campinas, 1994.

VAGO, Tarcísio. Início e fim do século XX: maneiras de fazer educação física na escola. Cadernos Cedes, São Paulo, ano XIX, n. 48, ago.1999. 


\title{
PHYSICAL EDUCATION TEACHERS' KNOWLEDGE OF THE FINAL YEARS OF ELEMENTARY SCHOOL
}

\begin{abstract}
The present study aimed to analyze how Physical Education teachers who work in the Final Years of Elementary School comprehend knowledge taught in class. It is a qualitative study in which five Physical Education teachers who work in town, state, and private schools in the city of Lajeado/RS were interviewed. The research results showed that comprehension of knowledge is closely connected to teachers' initial training and is clearly influenced by esportivization, militarism and hygienic medicine. Regarding to knowledge issues of discipline, interpersonal relations, and sports in educational and socialization perspective were evidently constructed based on bodily practices.
\end{abstract}

Key-words: Physical Education. Knowledge. Teachers. Elementary School.

\section{SABERES DE LOS PROFESORES DE EDUCACIÓN FÍSICA DE LOS AÑOS FINALES DE LA ENSEÑANZA PRIMARIA.}

Resumen: Esta investigación tuvo como objetivo analizar como los profesores de Educación Física que actúan en los Años Finales de la Enseñanza Primaria comprenden los saberes trabajados en sala de aula. Se trata de un estudio cualitativo en el que fueron entrevistados cinco profesores de Educación Física que actúan en escuelas de las redes municipal, estadual y privada de la ciudad de Lajeado/ RS. Los resultados de la investigación evidenciaron que la comprensión sobre los saberes está íntimamente conectada a la formación inicial de los profesores, notoriamente influenciada por la deportivación, el militarismo y la medicina higiénica. En relación a los saberes trabajados, se evidenció la cuestión de la disciplina, de las relaciones interpersonales, de los deportes en la perspectiva educacional y de la socialización, construidos a través de las prácticas corporales.

Palabras-clave: Educación Física. Saberes. Docentes. Enseñanza Primaria. 